INTESTINAL ANTISEPSIS, DIET AND CASTRATION IN RELATION TO EPILEPSY.

Read in the Section on Practice of Medicine, at the Forty-seventh Annual Meeting of the American Medical Association beld at Atlanta, Ga., May 5-8, 1896.

BY EVERETT FLOOD, M.D.

SUPERINTENDENT OF HOSPITAL COTTAGES FOR CHILDREN. BALDWINSVILLE, MASS.

The effort has been in the present paper to offer as briefly as possible some individual conclusions as to the advisability of employing the three methods enumerated in the title.

Pages have been filled, and can be again filled, with observations and statistics relating to the epileptic symptom. I leave aside now all that class of work and present these three as newer methods and those which to my mind promise, especially in young cases, rather better results than any plan with drugs as usually employed.

The first attack in many instances is after excessive eating, as in the following case: A girl of 14 ate heartily and hastily at dinner, then took a pint of peanuts on her way to school and, soon after the session opened, had a fit. She vomited large chunks of beef and a great quantity of other food. A second fit occurred three months later after another, though less, overindulgence in food; and they recurred at intervals, always with a similar apparent cause, though after the establishment of the habit the excess required was slight.

The person manifestly, in order to guide against excess and putrefaction as much as possible, ought from the outset of the child's life to have suitable food in right amount at proper intervals.

The gluttony of this class of persons is well known. Unrestricted they nearly all overeat. A sample supper recorded from an actual case, taken at random when no restraint was used was as follows: Boy of 14, six slices of bread and butter; one bowl of hulled corn and milk; three saucers of apple sauce; two cups of cocoa; three cookies.

Many such instances might be cited, though I am fully aware that the initial attack, when not traumatic, is not always traceable to the digestive overbalance.

To regulate and control the food of the child, when there is known to be danger, are rational methods of treatment and have actually proved effective in many instances. I have tested many drugs to a degree and still have observations going on, but $I$ believe more fully in prevention of this trouble than in a possible cure, and the suggestion has many times presented itself as to whether or not the good effects of certain drugs in special cases may be more due to their tendency to correct either putrefactive changes or parasitic influences than to any other quality. With this in view I have a number under various methods of drug treatment, but not as yet conclusive results to record. Auto-intoxication in diseases has received much well merited attention.

We are taught in the main merely a suitable choice of food, cleanliness, right living and to prevent putrefactive changes as far as we can by drugs or other methods. We have merely the same principles to follow when putrefaction takes places instead of wholesome digestion as in the instances where we seek relief from parasitic products and from other sepsis or toxins.

Intestinal parasites are unquestionably common. They are not conducive to the health of the child and it would be well if all could be removed. Doubtless such forms of life have their place in the economy of nature; but inside the human subject that place should eventually be taken by nutrient solutions, unsapped by even microörganisms, for the strengthening of the surrounding body. Dog breeders well know that all dogs have worms and that vermifuge will prevent or cure fits. The relatively longer intestinal tract in dogs very likely increases the animal's liability to have a fit. Chickens from incubators are apt to be abnormal, to have fits, deformities, etc., but I can not say that they have fewer intestinal parasites than the ordinary chicken. It is claimed that no dog can be reared free from such residents, whatever precaution may be taken with food and care; but I am of the opinion that no case has, as yet, been adequately tested to determine this point.

For purposes of disinfection and for destroying a part of the parasitic life large injections into the bowels, large draughts of water and perhaps the use of the ozone preparations give promise of some favorable results. Keeping the bowels open by suitable food and manner of life, massage of the abdomen, baths to aid digestion, and the measures before outlined, will certainly afford us a better outlook than the over-medication which has hitherto prevailed.

I have twenty-two cases of castration to report, twenty in males and two in females. I was first led to do a castration by my desire to do something to prevent masturbation in certain few boys who were also epileptic, and the habit is not as likely to become offensive in the non-epileptic. Castration as well as circumcision, which, if not God-given rites, are certainly worthy to have come from the mind of Deity conscious of the need of correcting a structural error, have bitter opponents. I would not be so unreasoning as to expect all men to agree even upon the most self-evident proposition. The opponents of vaccination are howling with as much persistency in the face of the most convincing statistics as they did at the beginning of the century when Jenner was promulgating his beliefs. The operation is old. I need not go into its history though a volume might be written thereon.

There is no doubt that the custom prevails in Eastern countries, as formerly, of emasculating certain youths to serve as safe attendants upon the royal women, and among another class for the purpose of keeping the youthful qualities of the voice.

As to the method of operation I may be allowed briefly to suggest that it seems an advantage to make one very small incision in the median line of the scrotum and then squeeze out each testicle successively through the opening. The cut is then easily closed with one stitch and the place being painted with co. tr. benzoin, always heals at once. There will be some induration of the stumps beneath the surface but this gradually absorbs and in a very few days the patient is in a safe position. I hardly dare to claim priority of use of this operation, but I certainly originated and used it without knowing of its application in any other quarter.

The effects of castration are, as far as I have observed them, as follows: The masturbation, which is the most important, finally ceases in all cases. Sometimes it persists for months with varying intensity, but it is not obtrusive even in these instances and eventually the habit is dropped. The boy gets plumper and has a clearer complexion. The voice is milder and pleas- 
anter and remains so if the case is a young one, at least for a few years, and probably permanently. The boy is less inclined to violence and domineering. The possibility of reproduction is of course eliminated. I consider this a most useful safeguard. I can not understand why any parent having such a son as we are considering should hesitate to have him castrated even if there were no other object than the last one named. No parent understanding the probability of inheritance in such a nervous case, ought to care to run the risk of becoming a grandparent. Sentiment is very wrong on most matters until set right by reason and education. So it is here. There is, however, some hope for spread of intelligence in such a matter as this, but judging from past progress I conclude that a hundred years of deliberation is likely to leave the public in much the same state of intelligence as at the present day. There has always been some fear among medical men that a male masturbator being castrated would fall into lasciviousness or into some other immorality worse than his first state. I do not find this fear substantiated in my cases. We had two boys who were kleptomaniacs as well as epileptic masturbators. For some weeks after the operation this manifestation was exaggerated, but it subsided entirely in a few weeks and only slight and infrequent traces have appeared for a year in one case and two in another. I find that these boys after operation do not entice other boys to masturbate. They have no tendency to think of sexual matters. The smutty story mania disappears and other unpleasant and gross manifestations are happily wanting.

The effect upon the force and frequency of the fits seems in all cases to be noticeable. There have been the same periods of fits and about the same length of period, but each fit has been less in time and milder in type.

Two females have been under my observations both of whom were castrated between the ages of 16 and 20. Certainly no general deductions can be made from so few cases but so far as my experience goes with them, I feel that the operation is not as thoroughly useful as with boys. There are, however, plenty of arguments to show that it is fully justifiable and might even be very desirable. To prevent conception is a very great desideratum, but to encourage the woman to safe and indiscriminate indulgence, which such a case would often be inclined to, would certainly be bad. The first two of these methods cut off in the offspring much of the unintellectualized emotional life which eventuate in the various neurotic disorders. The last is especially adapted to all those instances where we feel certain that marriage would never be proper.

DISCUSSION.

DR. G. W. WeBster, of Chicago-I assume that in the light of the most recent pathology, epilepsy may be said to be a condition of cortical instability. That is its essential underlying condition. It is characterized during the attacks by convulsive seizures, attended by loss of consciousness. If, then, we have, as a basis of the epilepsy, cortical instability, we must further recognize the fact that cortical instability may be influenced in many ways, directly, by the blood circulating in the cortical portion of the brain; and probably by uric acid and other waste products from the blood. This has led Haig and his supporters to hold that a large number of cases of epilepsy are due to uric acid circulating in the blood. The cortical portion of the brain may not only be influenced directly in the manner stated, but also by trauma, producing Jacksonian epi- lepsy. It may be influenced reflexly, and it is a matter of common knowledge that certain errors of refraction may produce epilepsy, and it was for this reason that a certain gentleman in New York a few years ago offered glasses or division of ocular muscles for the cure of all cases of epilepsy. We also know that in young boys irritation of the penis may result in epileptic seizures. I have seen the case of a child who was having as many as twelve to eighteen attacks in twenty-four hours, that had continued for a year and a half, cured simply by circumcision, we must remember, then, that we may have epilepsy as a reflex condition excited from the genital organs, from the eyes, from the intestines.

Dr. Louis Faugeres Bishop, of New York-It seems to me that in discussing epilepsy as a reflex result of irritation we are going backward. Epilepsy is an essential disease of the cortex of the brain, and the fact that a certain small proportion of cases are aggravated by local irritation is acknowledged by all. But I think the stund taken now in the Vanderbilt clinic, where they have seen many thousand cases of epilepsy, and they have been referred to various specialists for various kinds of treatment. We have had them circumcised, trephined, the nose and eyes treated, and so on. We think that a reflex cause of epilepsy is a very small factor and that it is hardly justifiable even to trephine. Our cures from trephining have all been temporary, and certainly if you trephine in a case where the source of irritation is right at the cortex, and you find that in spite of removal of that area the cure is only temporary, you would feel that anything like castration was hardly justifiable. Dr. Webster, of Chicago--The point which I insisted upon in the beginning of my remarks was, that the essential condition in epilepsy is one of cortical instability. That that brain, and the individual of which it forms a part, is what it is from two sources, heredity and environment; and that, given a child with a brain in this condition of cortical instability, treatment of the eye, castration, or anything else, will not change it, and we must recognize this cortical instability to begin with.

\section{EARLY DIAGNOSIS OF CARCINOMA THE STOMACH BY MEANS OF CHEMIC ANALYSIS OF THE GASTRIC CONTENTS.}

Read in the Section on Practice of Medicine. at the Forty-seventh Aunual Meeting of the American Medical Association, held at

BY W. C. WEBER, M.D. VISITING PHYSICIAN TO THE GERMAN HOSPITAL. CLEVELAND, OHIO.

The question of how to arrive at an early diagnosis of cancer of the stomach is certainly one which has attracted considerable interest in recent years, and hence concentrated efforts in the study of this peculiarly interesting disease. The reason of this becomes apparent in view of the fact that not infrequently cases come under one's observation which present few and indefinite objective symptoms and a vague sense of disturbance in the digestive process as the only subjective symptom of ailments which in their later stages prove unmistakably to be cancerous.

To proceed in the ordinary way, to palpate, percuss and gather the history of the case, is insufficient and often ends in negative and disappointing results. Such failures can, to a great extent, be obviated by supplementing the usual method of diagnosis with a process of chemic analysis to which the stomach contents are subjected.

The time was, not long since, when the absence of hydrochloric acid from the stomach contents was regarded as a symptom almost pathognomonic of car- 